Brachytherapy is a curative alternative to radical prostatectomy or external beam radiation [i.e. 3D conformal external beam radiation therapy (CRT), intensity-modulated radiation therapy (IMRT)] with comparable long-term survival and biochemical control and the most favorable toxicity. HDR brachytherapy (HDRBT) in treatment of prostate cancer is most frequently used together with external beam radiation therapy (EBRT) as a boost (increasing the treatment dose precisely to the tumor). In the early stages of the disease (low, sometimes intermediate risk group), HDR-BT is more often used as monotherapy. There are no significant differences in treatment results (overall survival rate - OS, local recurrence rate $-\mathrm{LC}$ ) between radical prostatectomy, EBRT and HDR-BT. Low-dose-rate brachytherapy (LDR-BT) is a radiation method that has been known for several years in treatment of localized prostate cancer. The LDR-BT is applied as a monotherapy and also used along with EBRT as a boost. It is used as a sole radical treatment modality, but not as a palliative treatment. The use of brachytherapy as monotherapy in treatment of prostate cancer enables many patients to keep their sexual functions in order and causes a lower rate of urinary incontinence. Due to progress in medical and technical knowledge in brachytherapy ("real-time" computer planning systems, new radioisotopes and remote afterloading systems), it has been possible to make treatment time significantly shorter in comparison with other methods. This also enables better protection of healthy organs in the pelvis. The aim of this publication is to describe both brachytherapy methods.

Key words: HDR brachytherapy, LDR brachytherapy, prostate cancer, seeds.

Contemp Oncol (Pozn) 2013; 17 (5): 407-412 DOI: $10.5114 /$ wo.2013.38557

\section{Brachytherapy in the therapy of prostate cancer - an interesting choice}

\author{
Janusz Skowronek ${ }^{12}$
}

${ }^{1}$ Brachytherapy Department, Greater Poland Cancer Center, Poznan, Poland 2Electroradiology Department, Poznan University of Medical Sciences, Poznan, Poland

\section{Introduction}

All the observations indicate a steady increase in prostate cancer incidence rate worldwide and in Poland. In 2000 a total of 5049 new cases were diagnosed in Poland, while in 2009 it was already 9142, which means a 55.2\% increase in 9 years [1]. In Poland this is the second (after lung cancer) most often diagnosed type of cancer in men. In many countries of the world it is the most frequently diagnosed type of cancer, e.g. in the USA in 2010 a total of 217,730 new prostate cancer cases were recorded (28\%) and 116,750 cases of lung cancer. A similar tendency is evident in many countries in Western Europe [2, 3]. More and more patients are diagnosed at the early stage of the disease, which enables effective treatment. This is further enhanced by the increasing popularity of the prostate-specific antigen (PSA) test.

The choice of the treatment modality of prostate cancer patients depends mainly on the stage of the disease and the prognostic factors [4]. A highly precise diagnosis of the progression of the disease is possible by means of imaging techniques such as computed tomography (CT), magnetic resonance imaging (MRI), and transrectal ultrasonography (TRUS), in parallel with clinical assessment (digital rectal examination - DRE) and PSA test results [5-8]. Knowledge of the TNM classification and results of pathology grading of the cancer makes it possible to select the appropriate treatment option. It is recommended to use the guidelines of ABS, GEC-ESTRO/EUA, NCCN and ASTRO [9-12].

There are many treatment options for cases of prostate cancer limited to the organ itself, as per the recommendations of most associations dealing with the treatment of such cases [9-15]. Treatment options include radical treatment (surgery, external beam radiation therapy, brachytherapy), active surveillance and in individual cases hormone therapy alone. Some physicians suggest that radical treatment methods should be offered to patients with an estimated survival time longer than 5-10 years [11]. Most physicians, however, tend to initiate treatment just because of the lack of possibilities to forecast the progression of cancer. It has also been observed that a younger age of incidence is usually associated with a higher risk of increased tumor malignancy. Brachytherapy of prostate cancer as monotherapy [this concerns both techniques - highdose-rate (HDR-BT) and low-dose-rate (LDR-BT)] is used more frequently, as it is associated with a smaller risk of potency disorders and urination disorders [16-21]. It is moreover better tolerated by patients burdened with different concomitant diseases, especially cardiological diseases, which disqualify the patient from surgical treatment. This method is also used in the case of patients who do not consent to surgery. For many men, an increasingly more important factor is the faster return to daily activities (including employment).

The aim of this paper is to describe both brachytherapy techniques used in the treatment of prostate cancer.

\section{Brachytherapy - general rules}

Brachytherapy (Greek brachy - from a small distance) is a method which employs the energy of photons and/or particles created by the decay of radioac- 
tive isotopes. Brachytherapy of prostate cancer is an interstitial brachytherapy (a source of radiation is put directly into the gland using applicators). The principle of brachytherapy is rapid decrease of the radiation dose (inversely proportional to the square of the distance) with increasing distance from the radioactive isotope. Compared to EBRT, brachytherapy increases the concentration of the dose within the tumor area, and enables the administration of increased fractionated doses and higher biological equivalent doses, while significantly reducing the time of treatment. Hospitals which use brachytherapy may benefit from the significant cost reduction associated with one-time anesthesia and application of isotopes (shorter in-patient treatment time). Obtaining good prostate cancer treatment results depends on selecting the right patients for treatment [4, 9-11].

According to the method of application and the power of the source dose in the target volume (prostatic gland), brachytherapy is divided into high-dose-rate brachytherapy (HDR-BT) and low-dose-rate brachytherapy (LDR-BT). Lowdose-rate brachytherapy is the implantation of low-dose-rate radioactive sources (seeds) into the prostatic gland, which stay inside until the end of the patient's life. This is usually done using iodine-125 (125I), palladium-103 (103 Pd) and cesium-131 $\left({ }^{131} \mathrm{Cs}\right)$ isotopes. High-dose-rate brachytherapy is a temporary type of brachytherapy where the high-dose-rate radioactive source [usually iridium $192(192 \mathrm{Ir})$ or cobalt $\left.60\left({ }^{60} \mathrm{Co}\right)\right]$ is inserted into the prostate from an afterloading machine during the temporary applicators implantation procedure.

Brachytherapy is used as the sole treatment method mainly in the low risk group. A large number of individual LDR-BT procedures are performed in this group of patients worldwide. This is supported by the very good treatment results reported in various publications, the relatively small number of side effects and the short time of treatment [22-27]. The procedure in which permanent implants are used is safe and does not require the use of special rooms with radiation shields, as is the case for HDR-BT. Moreover, due to the large competition between radiation source manufacturers in the
USA and the number of procedures performed, the cost of the procedure is relatively low and these procedures are commonly available $[9,14,28]$. The situation in Europe is different, as for at least 30 years HDR-BT has been developing in parallel [29-32]. High-dose-rate equipment is commonly available and the radioactive source used for treatment is the same as in the case of other neoplasms. The dwell-time position of the source in the applicators may be freely programmed during the procedure. The dwell times may be adapted to the requirements of treatment. In the course of treatment and the real-time planning procedure, the possibility of imprecise indication of the applicators' position in relation to the treated gland is minimal, which ensures high precision of the treatment.

Initially HDR-BT was introduced as a high-dose-rate supplement for EBRT and proved to be an effective and safe method of treatment [21, 22, 33, 34]. Treatment of patients from the low and intermediate risk groups with HDR-BT monotherapy was initiated at the end of the previous decade $[9,10,26,35-39]$.

\section{Patient selection for brachytherapy}

Selection of the method of brachytherapy for prostate cancer depends mainly on the stage of the disease, recommendations of the societies and the treatment capabilities of the center [4, 9-12]. Patients are usually divided into risk groups (Table 1) and selection criteria for treatment are usually based on the risk groups (Table 2 ). When analyzing the division of patients into risk groups for prostate cancer it is evident that the indications in the low risk group are clearly determined, whereas for the groups with a worse prognosis they differ. Patients who are appropriate candidates for HDR or LDR monotherapy usually belong to the low or sometimes intermediate risk group according to $\operatorname{ABS}[9,43]$. The National Comprehensive Cancer Network (NCCN) [11] recommends brachytherapy alone for the low risk group. These are patients with iPSA $\leq 10$, Gleason 2-6, T1-2a. International leading interstitial brachytherapy centers, which treat

Table 1. Comparison of prostate cancer patient risk groups

\begin{tabular}{|c|c|c|c|c|c|c|}
\hline Risk group & \multicolumn{2}{|c|}{ Very low risk } & Low risk & Intermediate risk & High risk & Very high risk \\
\hline Seattle/MSK & 〈CC [40] & - & $\begin{array}{c}\text { iPSA } \leq 10.0 \\
\text { and Gleason } 2-6 \\
\text { and } 11-2 b\end{array}$ & $\begin{array}{c}\text { iPSA }>10 \\
\text { or Gleason } \geq 7 \\
\text { or } \mathrm{T} \geq 2 \mathrm{c}\end{array}$ & $\begin{array}{l}2 \text { from } 3 \text { risk factors } \\
\text { from intermediate risk }\end{array}$ & - \\
\hline Mt. Sinai [41] & & - & $\begin{array}{c}\text { iPSA } \leq 10 \\
\text { and Gleason } 2-6 \\
\text { and } \mathrm{T} 1-2 \mathrm{a}\end{array}$ & $\begin{array}{l}\text { iPSA } 10-20 \\
\text { or Gleason } 7 \\
\text { or } \mathrm{T}=2 \mathrm{~b}\end{array}$ & $\begin{array}{c}2 \text { from } 3 \text { risk factors } \\
\text { from intermediate risk } \\
\text { or iPSA }>20 \mathrm{ng} / \mathrm{ml} \\
\text { or Gleason } 8-10 \text { or } T \geq 2 \mathrm{c}\end{array}$ & - \\
\hline D’Amico [42] & & - & $\begin{array}{c}\text { iPSA } \leq 10.0 \\
\text { and Gleason 2-6 } \\
\text { and } \mathrm{T} 1-2 \mathrm{a}\end{array}$ & $\begin{array}{c}\text { iPSA }=10-20 \\
\text { and/or Gleason } 7 \\
\text { and/or } \mathrm{T}=2 \mathrm{~b}\end{array}$ & $\begin{array}{c}\text { iPSA }>20 \mathrm{ng} / \mathrm{ml} \\
\text { or Gleason } 8-10 \text { or } \mathrm{T} \geq 2 \mathrm{c}\end{array}$ & - \\
\hline $\begin{array}{l}\text { NCCN [11] } \\
\text { th } \\
\text { PS }\end{array}$ & $\begin{array}{r}\text { Tla an } \\
\text { PSA }<1 \\
\text { tan } 3 \text { biop } \\
\leq \text { cance } \\
\text { SA densi }\end{array}$ & $\begin{array}{l}\text { Gleason } \leq 6 \\
\mathrm{ng} / \mathrm{ml} \text { fewer } \\
\text { sy cores positive, } \\
\mathrm{r} \text { in each one, } \\
\mathrm{y}<0.15 \mathrm{ng} / \mathrm{ml} / \mathrm{g}\end{array}$ & $\begin{array}{c}\text { iPSA } \leq 10.0 \\
\text { Gleason 2-6 } \\
\text { T1-2a }\end{array}$ & $\begin{array}{l}\text { iPSA } 10-20 \\
\text { or Gleason } 7 \\
\text { or T2b-2c }\end{array}$ & $\begin{array}{l}2 \text { from } 3 \text { risk factors } \\
\text { from intermediate risk } \\
\text { or iPSA > } 20 \mathrm{ng} / \mathrm{ml} \\
\text { or Gleason } 8-10 \text { or T3a }\end{array}$ & $\begin{array}{c}2 \text { from } 3 \text { risk factors } \\
\text { from high risk } \\
\text { or } \mathrm{T} 3 \mathrm{~b}-\mathrm{T} 42\end{array}$ \\
\hline
\end{tabular}

MSKCC - Memorial Sloan-Kettering Cancer Center; NCCN - National Comprehensive Cancer Network; *in NCCN recommendations there are two groups which are not mentioned in other classifications 
Table 2. Patient selection criteria for HDR-BT and LDR-BT according to ABS and GEC-ESTRO $[4,9,10,43]$

\begin{tabular}{|c|c|c|}
\hline $\begin{array}{l}\text { ABS } \\
\text { Prostate High-Dose-Rate Task Group }\end{array}$ & $\begin{array}{c}\text { ABS } \\
\text { Prostate Low-Dose-Rate Task Group }\end{array}$ & $\begin{array}{l}\text { GEC-ESTRO - High-Dose-Rate, } \\
\text { Low-Dose-Rate }\end{array}$ \\
\hline $\begin{array}{l}\text { Monotherapy } \\
\text { Clinical T1b-T2b } \\
\text { and Gleason score } \leq 7 \\
\text { and PSA } \leq 10 \mathrm{ng} / \mathrm{ml}\end{array}$ & $\begin{array}{c}\text { Clinical stage } \mathrm{T} 1 \mathrm{~b}-\mathrm{T} 2 \mathrm{~b} \\
\text { and Gleason score } \leq 6 \\
\text { and PSA } \leq 10 \mathrm{ng} / \mathrm{ml}, \\
\text { select higher risk patients, } \\
\text { salvage of select radiation therapy failures }\end{array}$ & $\begin{array}{l}\text { Clinical stage T1b-T2a } \\
\text { iPSA }<10 \mathrm{ng} / \mathrm{ml} \\
\text { Gleason max. } 6\end{array}$ \\
\hline $\begin{array}{l}\text { Boost } \\
\text { Patients with high risk features } \\
\text { such as T3-T4, Gleason score 7-10, } \\
\text { and/or PSA > } 10 \text { ng/ml } \\
\text { Selected patients with "bulky" } \\
\text { T1-2b tumor (inadequate information } \\
\text { exists to clearly define bulky tumor } \\
\text { based on DRE, TRUS, percentage } \\
\text { positive biopsies) }\end{array}$ & $\begin{array}{c}\geq \text { Clinical stage } \mathrm{T} 2 \mathrm{c} \\
\text { and/or Gleason score } \geq 7 \\
\text { and/or PSA }>10 \mathrm{ng} / \mathrm{ml}\end{array}$ & $\begin{array}{c}\text { Stages T1b-T3b } \\
\text { Any Gleason score } \\
\text { Any iPSA without distant metastases }\end{array}$ \\
\hline
\end{tabular}

Special clinical situations:
Inadequate information exists
to recommend supplemental EBRT
based on perineural invasion,
percent positive biopsies and/or
MRI-detected extracapsular penetration

$D R E$ - digital rectal examination; TRUS - transrectal ultrasound; EBRT - external beam radiation therapy; MRI - magnetic resonance imaging

patients with prostate cancer in the low risk group and sometimes patients in the intermediate risk group (T2b or iPSA $<15 \mathrm{ng} / \mathrm{ml}$ or Gleason $=7$ ) have a $95 \%$ cure rate $[35,44-46]$.

Patients suffering from prostate cancer in the intermediate risk group are the most heterogeneous group as far as possible methods of treatment are concerned. Patients in this group may be treated in accordance with several different protocols: combination therapy EBRT + HDR-BT boost, EBRT alone, or HDR-BT alone - all approaches together with short-term hormone therapy (usually 6 months). In the USA, patients in this group also undergo EBRT with LDR-BT.

In the low risk group the most often used method of treatment is HDR-BT (isotopes ${ }^{192} \mathrm{Ir},{ }^{60} \mathrm{Co}$ ) or LDR-BT alone (isotopes ${ }^{125}$ I, ${ }^{103} \mathrm{Pd},{ }^{131} \mathrm{Cs}$ ) and also EBRT alone or combined with HDR-BT. Some of the patients are operated on using different surgical techniques. Patients in this group do not usually require additional hormone therapy.

Prostate cancer in the high risk group without distant metastases and especially with a high value of the PSA test and $\mathrm{a} T \geq 2 \mathrm{c}$ should be treated with EBRT, possibly with irradiation of lymph nodes in the pelvis and boosting the local dose by means of brachytherapy together with long-term hormone therapy (contradicting recommendations include a treatment period of 2-3 years).

\section{Contraindications for brachytherapy [4]}

The most frequently cited contraindications for brachytherapy are: life expectancy of less than 5 years, distant metastases, history of transurethral resection of the prostate (TURP) with chronic, significant damage to the gland (in a period of 3 months before brachytherapy), and recurrent hematuria. Regular anticoagulation treatment should be interrupted at least 7 days prior to the implantation of radiation sources.
The volume of the gland should not exceed $60 \mathrm{~cm}^{3}$ (part of the gland lies closer to the pubic symphysis, which makes it harder to position the sources appropriately). It is possible to reduce the volume of the gland by administering hormone therapy for 3-6 months, which will enable a reduction of the volume of the gland in approximately $30 \%$ of patients $[22,31,47]$. Transurethral resection of the prostate (TURP) is a relative contraindication for brachytherapy and is associated with a higher rate ( $50 \%)$ of urinary incontinence after the procedure. Nevertheless, several publications did not confirm these data and proved that risk of this kind of complication is less than 10\% [48]. Contraindications for HDR-BT and LDR-BT according to ABS and GEC-ESTRO are presented in Table 3.

\section{Brachytherapy techniques [49]}

\section{Low-dose-rate brachytherapy}

Low-dose-rate brachytherapy is a radiation method that has been known for almost 30 years in treatment of localized prostate cancer. The main idea of this method is to implant small radioactive seeds as a source of radiation, directly into the prostate gland. Low-dose-rate brachytherapy is applied as a monotherapy and also used along with EBRT as a boost. It is used as a sole radical treatment modality, but not as a palliative treatment. The application of permanent seed implants is a curative treatment alternative in patients with organ-confined cancer, without extracapsular extension of the tumor [13, 14, 50-54]. Low-dose-rate brachytherapy represents the most conformal radiation therapy [55] and the number of patients referred for this radical treatment has grown rapidly in the last 15 years, especially in the United States $[4,14,16,34]$. There are several reasons why LDR-BT has achieved such popularity. Better toxicity profile with 
Table 3. Contraindications for HDR-BT and LDR-BT according to ABS and GEC-ESTRO $[4,9,10,43,49]$

\begin{tabular}{|c|c|c|}
\hline $\begin{array}{l}\text { ABS } \\
\text { Prostate High-Dose-Rate Task Group }\end{array}$ & $\begin{array}{c}\text { ABS } \\
\text { Prostate Low-Dose-Rate Task Group }\end{array}$ & $\begin{array}{l}\text { GEC-ESTRO - High-Dose-Rate, } \\
\text { Low-Dose-Rate }\end{array}$ \\
\hline $\begin{array}{l}\text { Relative contraindications } \\
\text { Severe urinary obstructive symptoms } \\
\text { Extensive TURP defect or TURP } \\
\text { within } 6 \text { months } \\
\text { Collagen vascular disease }\end{array}$ & $\begin{array}{l}\text { Severe urinary irritative/obstructive symptomatology } \\
\text { Extensive TURP defect } \\
\text { Substantial median lobe hyperplasia } \\
\text { Prostate dimensions larger } \\
\text { than the grid (i.e., > } 60 \mathrm{~mm} \text { in width } \\
\text { and }>50 \mathrm{~mm} \text { in height) } \\
\text { Severe pubic arch interference } \\
\text { Gross seminal vesicle involvement } \\
\text { Prior pelvic radiotherapy } \\
\text { Inflammatory bowel disease }\end{array}$ & $\begin{array}{c}\text { Volume }>60 \mathrm{~cm}^{3} \\
\text { TURP within } 6 \text { months } \\
\text { Infiltration of the external sphincter } \\
\text { of the bladder neck } \\
\text { Significant urinary obstructive symptoms } \\
\text { Pubic arch interference } \\
\text { Rectum-prostate distance on TRUS }<5 \mathrm{~mm} \\
\text { Lithotomy position or anesthesia not possible }\end{array}$ \\
\hline $\begin{array}{l}\text { Absolute contraindications } \\
\text { Unable to undergo anesthesia } \\
\text { (general, spinal, epidural, or local) } \\
\text { Unable to lie flat }\end{array}$ & $\begin{array}{c}\text { Distant metastases } \\
\text { Life expectancy }<5 \text { years }\end{array}$ & \\
\hline
\end{tabular}

Table 4. Doses for HDR-BT and LDR-BT according to ABS and ESTRO/EAU/EORTC $[9,43,49,53]$

\begin{tabular}{|c|c|}
\hline $\begin{array}{l}\text { ABS Prostate } \\
\text { High-Dose-Rate Task Group }\end{array}$ & $\begin{array}{c}\text { ABS Prostate } \\
\text { Low-Dose-Rate Task Group } \\
\text { and ESTRO/EAU/EORTC } \\
\text { Low-Dose-Rate }\end{array}$ \\
\hline $\begin{array}{l}\text { Monotherapy } \\
10.5 \text { Gy } \times 3 \\
8.5-9.5 \text { Gy } \times 4 \\
6.0-7.5 \text { Gy } \times 6\end{array}$ & $\begin{array}{c}{ }^{103} \mathrm{Pd} \text { - median } 125 \text { Gy (110-120 Gy) } \\
\text { 125I - median } 145 \text { Gy (140-160 Gy) } \\
{ }^{131} \mathrm{Cs}-115 \text { Gy }\end{array}$ \\
\hline $\begin{array}{l}\text { BT + EBRT } \\
15 \text { Gy × } 1 \text { (with 36-40 Gy EBRT } \\
9.5-10.5 \text { Gy } \times 2 \\
\text { (with } 40-50 \text { Gy EBRT) } \\
5.5-7.5 \text { Gy } \times 3 \\
\text { (with 40-50 Gy EBRT) } \\
\text { 4.0-6.0 Gy × } 4 \\
\text { (with 36-50 Gy EBRT) }\end{array}$ & $\begin{array}{c}\text { 103Pd } \\
\text { Boost (with 41.4-50.4 Gy EBRT) } \\
90-100 \text { Gy } \\
125 \text { | } \\
\text { Boost (with 41.4-50.4 Gy EBRT) } \\
\text { 108-110 Gy }\end{array}$ \\
\hline
\end{tabular}

$B T$ - brachytherapy; EBRT - external beam radiation therapy

a higher dose applied to the prostate gland are the main advantages for brachytherapy in comparison with EBRT. Compared with radical prostatectomy, permanent seed implantation is a short, one-day therapy with a lower complication rate during and after the procedure (bleeding, urinary incontinence, impotence) [27]. Specific selection of radioactive isotopes and their correct localization allow a high dose to be deposited into the prostate tumor with a rapid fall-off of the dose outside the area of treatment and - at the same time - allows preservation of organs at risk (OaRs) [56, 57].

\section{High-dose-rate brachytherapy}

High-dose-rate brachytherapy is a temporary type of brachytherapy where the high-dose-rate radioactive source [usually iridium $192(192 \mathrm{Ir})$ or cobalt $60\left({ }^{60} \mathrm{Co}\right)$ ] is inserted into the gland during the applicators implantation procedure. In Europe, since at least 30 years ago, HDR-BT has been developed in parallel to LDR-BT $[10,22,29,32,58]$ and, during the last years, also it is being used in the USA with growing interest. HDR equipment is commonly available and the radioac- tive source used for treatment is the same as in the case of other neoplasms. The dwell-time position of the source in the applicators may be freely programmed during the procedure. The dwell-time may be adapted to the requirements of treatment [59]. In the course of treatment and the realtime planning procedure the possibility of imprecise indication of the applicators' position in relation to the treated gland is minimal, which ensures high precision of the treatment.

\section{Brachytherapy doses [49]}

According to ABS recommendations, patients with organconfined prostate cancer are to be treated with monotherapy, and others with combined treatment [EBRT in 40-50 Gy dose with BT boost of 110 Gy and 100 Gy depending on which EBRT dose was administered (LDR-BT) or different HDR-BT schemas]. The HDR-BT procedure is performed once or repeated several times, depending on the fractionating schema assumed. The ABS proposes three fractionating schemas for HDR-BT monotherapy and four schemas for combined treatment [9], although other schemas are also applied (Table 4). Depending on the mode of fractionation, the fractionated doses are administered in one session at time intervals (e.g. every 6 hours) or are repeated in the course of subsequent procedures. Some centers use the $3 \times 10.5-11$ Gy fractionation scheme with a 1-2-week interval between fractions. Many different fractionation schemes make it difficult to compare treatment results. LDR-BT doses have been used for years and do not undergo significant changes. Perhaps our knowledge about apprioprate dose rate will expand after confirming the importance of the introduction of molecular tests during histopathological examination [60, 61].

In conclusion, radiobiological models support the current clinical evidence for equivalent outcomes in localized prostate cancer with either LDR or HDR brachytherapy using current dose regimens. At present, the available clinical data with these two techniques suggest that they are equally effective, stage by stage, in providing high tumor control rates. High-dose-rate brachytherapy has an important role in the treatment of prostate cancer in combination therapy (EBRT 
+ HDR-BT). The HDR-BT monotherapy has been used for more than ten years and its benefits ensure a certain advantage over other methods of treatment. This is a method which allows a high dose to be deposited in a very fast and precise manner in the immobilized organ, minimizing the irradiation of neighboring organs, personnel and the patient's family. Several hundred thousand patients have been treated with LDR-BT, with experience over 15 years and more in major centers in the US and Europe. Results are mature and well established, and mainly related to the risk group of the patient. LDR-BT has been a gold standard for prostate brachytherapy in low risk patients for many years in a lot of countries. It is a convenient technique for a patient. On the other hand, HDR-BT is more cost effective, with reimbursement in many countries, and results for HDR-BT monotherapy are very promising.

\section{The author declares no conflict of interests.}

\section{References}

1. National Cancer Register Oncology Centre in Warsaw (access: 15.12.2011 - http://85.128.14.124/krn/).

2. Jemal A, Bray F, Center MM, Ferlay J, Ward E, Forman D. Global cancer statistics. CA Cancer J Clin 2011; 61: 69-90.

3. Bracarda S, de Cobelli O, Greco C, Prayer-Galetti T, Valdagni R, Gatta G, de Braud F, Bartsch G. Cancer of the prostate. Crit Rev Onco Hematol 2005; 56: 379-96.

4. Skowronek J. Low-dose-rate or high-dose-rate brachytherapy in treatment of prostate cancer - between options. J Contemp Brachytherapy 2013; 5: 33-41.

5. Wojcieszek P, Białas B. Prostate cancer brachytherapy: guidelines overview. J Contemp Brachytherapy 2012; 4: 116-20.

6. Pieters B, Wijkstra H, van Herk M, Kuipers R, Kaljouw E, de la Rosette J, Koning C. Contrast-enhanced ultrasound as support for prostate brachytherapy treatment planning. I Contemp Brachytherapy 2012; 4: 69-74.

7. Kaljouw E, Pieters B, Koedooder K, Lucas C, Koning C. Benefits of a dual sagittal crystal transducer for ultrasound imaging during I 125 seed implantation for permanent prostate brachytherapy. I Contemp Brachytherapy 2012; 4: 141-5.

8. Reed G, Cunha JA, Noworolski S, Kurhanewicz J, Vigneron D, Hsu IC, Pouliot J. Interactive, multi-modality image registrations for combined MRI/MRSI-planned HDR prostate brachytherapy. J Contemp Brachytherapy 2011; 3: 26-31.

9. Hsu I-Ch, Yamada Y, Vigneault E, Pouliot J. American Brachytherapy Society Prostate High-Dose Rate Task Group. Retrieved 15-03-2010, 2010, from http://www.americanbrachytherapy.org/guidelines/ index.cfm.

10. Kovács G, Pötter R, Loch T, Hammer J, Kolkman-Deurloo IK, de la Rosette JJ, Bertermann H. GEC/ESTRO-EAU recommendations on temporary brachytherapy using stepping sources for localised prostate cancer. Radiother Oncol 2005; 74: 137-48.

11. Mohler J, Bahnson RR, Boston B, et al. NCCN clinical practice guidelines in oncology: prostate cancer. J Natl Compr Canc Netw 2010; 8: 162-200.

12. Erickson BA, Demanes DJ, Ibbott GS, et al. American Society for Radiation Oncology (ASTRO) and American College of Radiology (ACR) Practice Guideline for the performance of High-Dose-Rate Brachytherapy. Int J Radiat Oncology Biol Phys 2011; 79: 641-9.

13. Horwich A, Parker C, Bangma C, Kataja V. ESMO Guidelines Work ing Group. Prostate cancer: ESMO Clinical Practice Guidelines for diag nosis, treatment and follow-up. Ann Oncol 2010; Suppl 5: 129-33.

14. Thompson I, Thrasher JB, Aus G, et al. Guidelines for the management of clinically localized prostate cancer: 2007 update. J Urol 2007; 177: 2106-31.
15. Heidenreich A, Bellmunt J, Bolla $M$, et al. EAU Guidelines on Prostate Cancer. Part 1: Screening, Diagnosis, and Treatment of Clinically Localised Disease. Eur Urol 2011; 59: 61-71.

16. Crook JM, Gomez-Iturriaga A, Wallace K, Ma C, Fung S, Alibhai S, Jewett M, Fleshner N. Comparison of health-related quality of life 5 years after SPIRIT: Surgical Prostatectomy Versus Interstitial Radiation Intervention Trial. J Clin Oncol 2011; 29: 362-8.

17. Samuelian JM, Swanson DA, Kudchadker RJ, et al. Long-term tumor control after brachytherapy for base of prostate cancer. J Contemp Brachyther 2011; 3: 183-187.

18. Talcott JA, Manola J, Clark JA, et al. Time course and predictors of symptoms after primary prostate cancer therapy. J Clin Oncol 2003; 21: 3979-3986.

19. Salembier C, Rijnders A, Henry A, Niehoff P, André Siebert F, Hoskin P. Prospective multi-center dosimetry study of low-dose lodine-125 prostate brachytherapy performed after transurethral resection. J Contemp Brachytherapy 2013; 5: 63-9.

20. Aronowitz JN, Rivard MJ. The phylogeny of permanent prostate brachytherapy. J Contemp Brachytherapy 2013; 5: 89-92.

21. Jo Y, Junichi H, Tomohiro F, Yoshinari I, Masato F. Radical prostatectomy versus high-dose rate brachytherapy for prostate cancer: effects on health-related quality of life. BJU Int 2005; 96: 43-7.

22. Chicheł A, Kanikowski M, Skowronek J, Dymnicka M, Piotrowski T. Correlation between treatment plan parameters and particular prognostic factors in prostate cancer treated with high-dose-rate brachytherapy (HDR-BT) as a boost. J Contemp Brachytherapy 2009; 1: 11-7.

23. Peeters ST, Heemsbergen WD, van Putten WL, Slot A, Tabak H, Mens JW, Lebesque JV, Koper PC. Acute and late complications after radiotherapy for prostate cancer: results of a multicenter randomized trial comparing 68 Gy to 78 Gy. Int J Radiat Oncol Biol Phys 2005; 61: 1019-34.

24. Machtens S, Baumann R, Hagemann J, Warszawski A, Meyer A, Karstens JH, Jonas U. Long-term results of interstitial brachytherapy (LDR-Brachytherapy) in the treatment of patients with prostate cancer. World J Urol 2006; 24: 289-95.

25. Makarewicz R, Lebioda A, Terlikiewicz J, Biedka M, Wiśniewski T. PSA bouncing after brachytherapy HDR and external beam radiation therapy: a study of 121 patients with minimum 5-years follow-up. J Contemp Brachytherapy 2009; 1: 92-6.

26. Martinez AA, Demanes J, Vargas C, Schour L, Ghilezan M, Gustafson GS. High-dose-rate prostate brachytherapy: an excellent acceleratedhypofractionated treatment for favorable prostate cancer. Am J Clin Oncol 2010; 33: 481-8.

27. Jacobs BL, Smith RP, Beriwal S, Benoit RM. Changes in lower urinary tract symptoms after prostate brachytherapy. J Contemp Brachytherapy 2011; 3: 115-20.

28. Sylvester JE, Grimm PD, Wong J, Galbreath RW, Merrick G, Blasko JC. Fifteen-year biochemical relapse-free survival, cause-specific survival, and overall survival following I-125 prostate brachytherapy in clinically localized prostate cancer: Seattle experience. Int J Radiat Oncol Biol Phys 2011; 81: 376-81.

29. Seppenwoolde Y, Kolkman-Deurloo IK, Sipkema D, de Langen M, Praag J, Jansen P, Heijmen B. HDR prostate monotherapy - dosimetric effects of implant deformation due to posture change between TRUSand CT-imaging. Radiother Oncol 2008; 86: 114-9.

30. Martin T, Baltas D, Kurek R, et al. 3-D conformal HDR brachytherapy as monotherapy for localized prostate cancer. A pilot study. Strahlenther Onkol 2004; 180: 225-32.

31. Kanikowski M, Skowronek J, Chicheł A. HDR brachytherapy of prostate cancer - two year's experience in Greater Poland Cancer Centre. J Contemp Brachytherapy 2009; 1: 137-44.

32. Galalae RM, Kovács G, Schultze J, et al. Long-term outcome after elective irradiation of the pelvic lymphatics and local dose escalation using high-dose-rate brachytherapy for locally advanced prostate cancer. Int J Radiat Oncol Biol Phys 2002; 52: 81-90.

33. Martinez AA, Gustafson G, Gonzalez J, et al. Dose escalation using conformal high-dose-rate brachytherapy improves outcome in unfavorable prostate cancer. Int J Radiat Oncol Biol Phys 2002; 53 : 316-27.

34. Demanes DJ, Rodriguez RR, Altieri GA. High dose rate prostate brachytherapy: the California Endocurietherapy (CET) method. Radiother Oncol 2000; 57: 289-96. 
35. Demanes DJ, Martinez AA, Ghilezan M, Hill DR, Schour L, Brandt D, Gustafson G. High-dose-rate monotherapy: safe and effective brachytherapy for patients with localized prostate cancer. Int J Radiat Oncol Biol Phys 2011; 81: 1286-92.

36. Rogers L, Rogers LI. Extended followup of high-dose-rate brachytherapy as monotherapy for intermediate- risk prostate cancer. Brachytherapy 2010; 9 (Suppl. 1): S55-S6.

37. Yoshioka Y, Konishi K, Oh RJ, et al. High-dose-rate brachytherapy without external beam irradiation for locally advanced prostate cancer. Radiother Oncol 2006; 80: 62-8.

38. Yoshioka Y, Konishi K, Sumida I, et al. Monotherapeutic high-doserate brachytherapy for prostate cancer: five-year results of an extreme hypofractionation regimen with 54 Gy in nine fractions. Int J Radiat Oncol Biol Phys 2011; 80: 469-75.

39. Martinez AA, Pataki I, Edmundson G, Sebastian E, Brabbins D, Gustafson G. Phase II prospective study of the use of conformal highdose-rate brachytherapy as monotherapy for the treatment of favorable stage prostate cancer: a feasibility report. Int J Radiat Oncol Bio Phys 2001; 49: 61-9.

40. Sylvester JE, Blasko JC, Grimm PD, Meier R, Malmgren JA. Ten-year biochemical relapse-free survival after external beam radiation and brachytherapy for localized prostate cancer: the Seattle experience. Int J Radiat Oncol Biol Phys 2003; 57: 944-52.

41. Lee LN, Stock RG, Stone NN. Role of hormonal therapy in the management of intermediate- to high-risk prostate cancer treated with permanent radioactive seed implantation. Int J Radiat Oncol Biol Phys 2002; 52: 444-52.

42. D'Amico AV, Whittington R, Malkowicz SB, et al. Clinical utility of the percentage of positive prostate biopsies in defining biochemical outcome after radical prostatectomy for patients with clinically local ized prostate cancer. J Clin Oncol 2000; 18: 1164-72.

43. Merrick GS, Zelefsky M, Sylvester K, Nag S, Bice W. American Brachytherapy Society Prostate Low-Dose Rate Task Group. http://www. americanbrachytherapy.org/guidelines/prostate_low-doseratetaskgroup.pdf

44. Yoshioka Y, Konishi K, Oh RJ, et al. High-dose-rate brachytherapy without external beam irradiation for locally advanced prostate cancer. Radiother Oncol 2006; 80: 62-8.

45. Yoshioka Y, Nose T, Yoshida K, et al. High-dose-rate interstitial brachytherapy as a monotherapy for localized prostate cancer: treat ment description and preliminary results of a phase I/II clinical trial. Int J Radiat Oncol Biol Phys 2000; 48: 675-81.

46. Corner C, Rojas AM, Bryant L, Ostler P, Hoskin P. A Phase II study of high-dose-rate afterloading brachytherapy as monotherapy for the treatment of localized prostate cancer. Int J Radiat Oncol Biol Phys 2008; 72: 441-6.

47. Kucway R, Vicini F, Huang R, Stromberg J, Gonzalez J, Martinez A. Prostate volume reduction with androgen deprivation therapy before interstitial brachytherapy. J Urol 2002; 167: 2443-7.

48. Wallner K, Lee H, Wasserman S, Dattoli M. Low risk of urinary incontinence following prostate brachytherapy in patients with a prior transurethral prostate resection. Int J Radiat Oncol Biol Phys 1997; 37: 565-9.

49. Skowronek J. Modern brachytherapy in the treatment of prostate cancer. Global Journal of Oncologist 2013; 1: 30-41.

50. Nag S, Beyer D, Friedland J, Grimm P, Nath R. American Brachytherapy Society (ABS) recommendations for transperineal permanent brachytherapy of prostate cancer. Int I Radiat Oncol Biol Phys 1999; 44: 789-99.

51. Porter AT, Blasko JC, Grimm PD, Reddy SM, Ragde H. Brachytherapy for prostate cancer. Cancer J Clin 1995; 45: 165-78.

52. Garbaulet A, Potter R, Mazeron JJ, Meertens H, Van Limbergen E (eds). The GEC ESTRO Handbook of Brachytherapy. Chapter 20. Brussels 2002; 473-80.

53. Ash D, Flynn A, Battermann J, de Reijke T, Lavagnini P, Blank L. ESTRO/EAU/EORTC recommendations on permanent seed implantation for localized prostate cancer. Radiother Oncol 2000; 57 : 315-21.

54. Skowronek J, Kanikowski M, Zwierzchowski G, Chicheł A. Brachyterapia LDR w leczeniu raka gruczołu krokowego. Contemp Oncol (Pozn) 2009; 13: 316-29 [In Polish].
55. Polo A. Image fusion techniques in permanent seed implantation. J Contemp Brachytherapy 2010; 2: 98-106.

56. Pujades MC, Camacho C, Perez-Calatayud J, et al. The use of nomograms in LDR-HDR prostate brachytherapy. J Contemp Brachyther 2011; 3: 121-4.

57. Knaup C, Mavroidis P, Stathakis S, Smith M, Swanson G, Papanikolaou N. Evaluation of the effect of prostate volume change on tumor control probability in LDR brachytherapy. J Contemp Brachytherapy 2011; 3: 125-30.

58. Martin T, Baltas D, Kurek R, et al. 3-D conformal HDR brachytherapy as monotherapy for localized prostate cancer. A pilot study. Strahlenther Onkol 2004; 180: 225-232.

59. Chao ST, Angermeier K, Klein EA, Reddy CA, Ulchaker JC, Stephenson A, Campbell S, Ciezki JP. Prophylactic urethral stenting with Memokath ${ }^{\circledR} 028 \mathrm{SW}$ in prostate cancer patients undergoing prostate $125 \mathrm{I}$ seed implants: phase I/II study. J Contemp Brachytherapy 2011; 3: 18-22.

60. Łuczyńska E, Gasińska A, Wilk W. Microvessels density and expression of vascular endothelial growth factor in clinically localized prostate cancer. Pol J Pathol 2013; 64: 33-8.

61. Łuczyńska E, Gasińska A, Wilk W. Expression of Ki-67 (MIB-1) and GLUT-1 proteins in non-advanced prostatic cancer. Pol J Pathol 2012; 63: 272-7.

\section{Address for correspondence}

Janusz Skowronek MD, PhD, Assist. Prof.

Brachytherapy Department

Greater Poland Cancer Center

Garbary 15

61-866 Poznan, Poland

tel. +48618850818

fax +48618850834

e-mail: janusz.skowronek@wco.pl

Submitted: 27.09.2013

Accepted: $\quad$ 18.10.2013 